\title{
A Pattern Analysis of Daily Electric Vehicle Charging Profiles: Operational Efficiency and Environmental Impacts
}

\author{
Ranjit R. Desai, Roger B. Chen (D), and William Armington \\ Golisano Institute for Sustainability, Rochester Institute of Technology, One Lomb Memorial Dr., Rochester, NY 14623-5608, USA \\ Correspondence should be addressed to Roger B. Chen; rbcgis@rit.edu
}

Received 16 May 2017; Revised 16 October 2017; Accepted 16 November 2017; Published 17 January 2018

Academic Editor: Jing Dong

Copyright (C) 2018 Ranjit R. Desai et al. This is an open access article distributed under the Creative Commons Attribution License, which permits unrestricted use, distribution, and reproduction in any medium, provided the original work is properly cited.

\begin{abstract}
Plug-in Electric Vehicles (PEVs) are considered one solution to reducing GHG emissions from private transport. Additionally, PEV adopters often have free access to public charging facilities. Through a pattern analysis, this study identifies five distinct clusters of daily PEV charging profiles observed at the public charging stations. Empirically observed patterns indicate a significant amount of operational inefficiency, where $54 \%$ of the total parking duration PEVs do not consume electricity, preventing other users from charging. This study identifies the opportunity cost in terms of GHG emissions savings if gasoline vehicles are replaced with potential PEV adopters. The time spent in parking without charging by current PEV users can be used by these potential PEV users to charge their PEVs and replace the use of gasoline. The results suggest that reducing inefficient station use leads to significant reductions in emissions. Overall, there is significant variability in outcomes depending on the specific cluster membership.
\end{abstract}

\section{Introduction and Background}

In the United States, the newly registered number of Battery Electric Vehicles (BEVs) and Plug-in Electric Vehicles (PEVs) increased by 159,616 in the year 2016 alone [1]. Though this is not a significant market share, the PEV penetration rate, BEVs and PEVs considered together, is considerably high in the private transportation market. This has led policy-makers to reconsider infrastructure planning to accommodate increasing PEVs and assess sustainability implications of infrastructural development. Recently, a report prepared for the Clinton Climate Initiative [2] outlined the incumbent and future issues of increasing penetration of PEVs. At the forefront there are the adequacy and level-of-service (LOS) of charging stations; these issues are further underscored by the increasing need for out-ofhome PEV charging opportunities. A critical component for management and decision-making regarding out-ofhome charging decisions is the demand for these services, governed by drivers' charging behaviors. Understanding the timing and duration of PEV charging decisions supports making infrastructure and operational policies that meet economic, operational efficiency, and environmental objectives.
The literature on assessing PEV charging has grown significantly in the past decade, generating studies that investigate both quantitative and qualitative issues. The literature can be roughly segmented into three areas: (i) consumer adoption and use; (ii) infrastructure performance and evaluation; and (iii) operational issues of stations.

1.1. Consumer PEV Adoption. The literature on consumer adoption and use has focused on identifying groups of PEV drivers with respect to their technology ownership and interaction with the infrastructure. One study $[3,4]$ identifies three groups based on adopters and potential PEV owners in China: (a) early adopters, (b) shapeable groups, and (c) late adopters, each consisting of two motivations that have their own set unique behaviors. For example, early adopters have behaviors labeled as trendy greens and running cost sensitive. Another study [5] assesses PEV charging behavior by applying a "user-battery interaction style" metric developed originally for small electronic devices to find out similarities in device use. In another study [6] PEV drivers were interviewed and found to generally manage without public infrastructure, with the battery still containing plenty of range when station recharging was initiated. 
Although PEV range is typically adequate for completing most daily home-based tours without intermediate charging [7], continued PEV adoption, as technological forecasts indicate, can benefit from continued installation and planning of out-of-home charging [8], in addition to further considering PEV driver's perceptions and experiences at stations. Although consumer interviews and analogous insights from the literature are helpful for describing charging behaviors, a study defining user groups or "market segments" based on a pattern analysis of empirical time-dependent charging data from out-of-home charging stations is absent in the literature. Such a study could contribute greatly to helping effective policy implementation from both an operational and sustainability impact perspective.

1.2. Infrastructure Performance and Evaluation. PEV adoption will also impact the electric grid and shift environmental impact from point-source vehicle to electricity generator emissions due to increasing electricity demand. The literature has produced work on network optimization models that quantify and assess infrastructure and environmental impacts at the network level. These studies consider developing public charging infrastructure $[9,10]$ by optimizing social welfare relative to impacts on the electrical grid. Other studies assess the electric grid impacts from widespread charging through conventional travel surveys, where travel logs of PEV drivers [11] from the NHTS are used to predict electricity consumption and load profiles. Other studies further expand on these by applying network charging scheduling [12] and time-of-use rates [13] to optimize and assess electrical loads on the infrastructure. In another study, large-scale vehicle survey data [14] are used to model charging location decisions by maximizing PEV driving miles to jointly maximum environmental benefit. An activity-based modeling approach [15] was used in another study to assess PEV environmental impacts, suggesting that public charging facilities allow charging during the daytime and can potentially reduce emissions. Although observed travel data is used in these studies, the effects of individual charging behaviors at the stations themselves have not been examined and operational inefficiencies in station turnaround are not considered.

1.3. Operational Issues at Charging Stations. Operational issues have also been considered in the literature. Interviews [16] of PEV owners conducted assessed perceptions of charging etiquette at public and workplace charging locations, concluding that no common charging guidelines evolved unless a pathway of communication between users exists, which ultimately leads to inefficiency in infrastructure use. Another study [17] addresses these inefficiencies by considering occupancy rates, infrastructure costs, and parking premiums to assess the economic feasibility of deploying charging stations using an economic model. This study also finds that policies that promote more infrastructure development and increased station usage are beneficial to decrease range-anxiety issues and charging premiums from the user perspective [17]; however, no empirical data was used. It is important to note that the PEV charging behavior at the public charging stations is not studied before, and therefore the uniqueness of this analysis is; this study brings into light the insights to charging behavior characteristics using pattern analysis of daily charging profiles observed at public charging stations and is supported by dataset.

The overarching goal of this study is to characterize the observed PEV daily charging patterns and assess the environmental impacts. One main task is to identify potential market segments based on the observed patterns of actual PEV adopters at existing charging stations. The focus of this study is to analyze the charging behavior of PEV users at the public charging stations. However, the fundamental unit of this analysis is not a PEV user but a charging profile observed in a single day (as shown later in Figure 2). A second task is to calculate the opportunity cost for improving operational efficiency and environmental impacts. The identified segments are used as a basis to accomplish this scenario analysis. The efficient operations scenario calculates the GHG emissions savings from reducing the duration of parking without charging, allowing other potential PEV drivers and adopters to charge. This displaces gasoline miles that potential PEV drivers would otherwise have incurred from inability to use their PEVs. The dataset lacks information about the PEV users who could not get the access to charging stations if they were occupied (denoting latent demand); the smart charging stations do not have a mechanism to keep track of this parameter. Furthermore, determining latent demand for public infrastructure, such as roads, is in its own right a difficult problem [18]. Similarly, the demand for public charging stations is difficult to determine. In case of the City of Rochester, authorities have confirmed in the personal discussion that there have been instances when PEV users could not get access to public charging stations because all the charging stations at the particular location were occupied. Furthermore, the authors have noted that for extended periods the data shows stations occupied continuously, where a PEV occupies the station just as one PEV departs. Further investigations into this queueing phenomena are underway by the authors.

The City of Rochester, for a population of 208,880 [18] -as of July 1, 2016-has 28 level 2 [19] (with J1772 connector) public charging stations installed and operating through ChargePoint network [20, 21]. Each level 2 charging station can accommodate two PEVs at a time. Therefore, if all the charging stations in the City of Rochester are occupied at a time, there should be 56 PEVs pluggedin to charging stations. In the upstate New York region, Buffalo, NY (population 256,902 [18]), has 29 [19] level 2 and Syracuse, NY (population 143,378 [18]), has 27 public charging stations through ChargePoint network. The data used for this analysis is collected from charging event logs collected at these 28 [19] level 2 smart public charging stations installed in the City of Rochester. The charging stations were installed as part of a New York State Energy Research and Development Authority (NYSERDA) grant to the City of Rochester and are managed by ChargePoint Inc. [21]. For this work, these charging stations are heuristically grouped-as explained in the next section-into three main locations (Figure 1). 

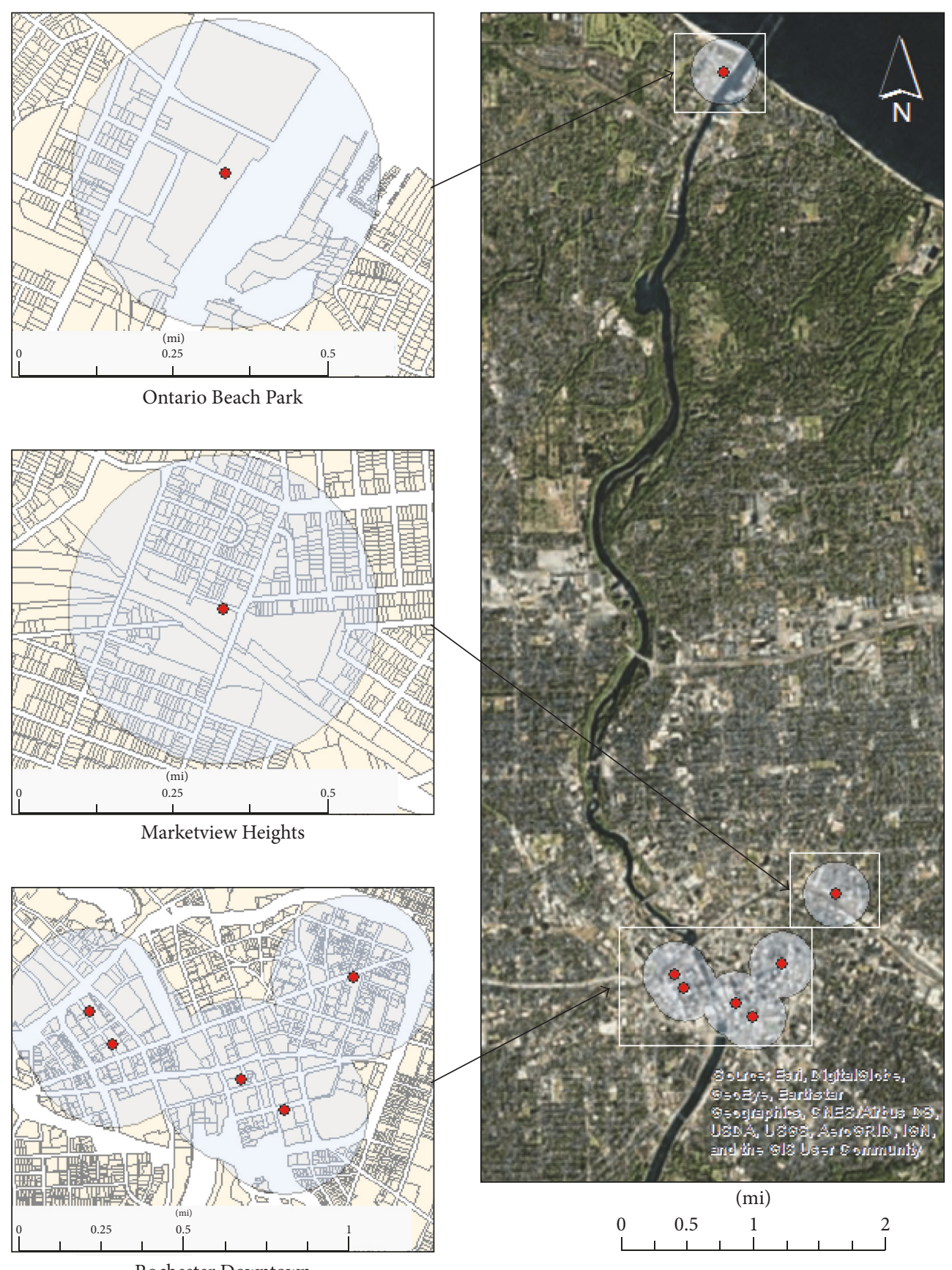

Rochester Downtown

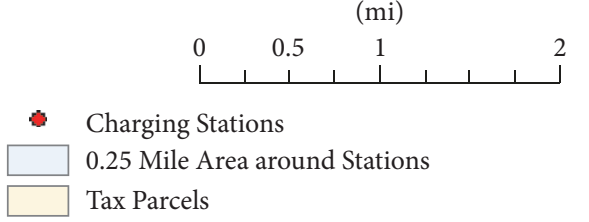

FIGURE 1: Location of charging stations in the City of Rochester (with 1/4 mile radius).

\section{Dataset}

The City of Rochester currently owns and maintains seven public smart charging stations that log the charging activities of vehicles using the stations. Types of data collected through these stations include (i) timestamps of charging events, such as the time PEVs plug-in at the stations; (ii) computed performance metrics, such as energy consumed (kWh); and (iii) other station information. The data used in the analysis were collected over a period of more than two years between March 2014 and May 2016. Charging station location coordinates were extracted and charging stations were grouped heuristically into three distinct areas: (i) Rochester Downtown (RDT), (ii) Marketview Heights (MVH), and (iii) Ontario Beach Park (OBP). The RDT extent which is defined by the area outlined by the Rochester Downtown Development 


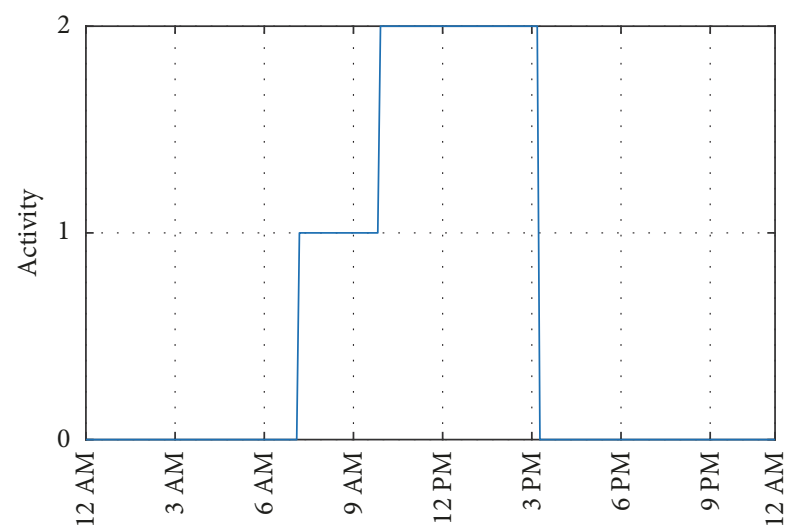

(a) User ID: 137113 (11/26/2014)

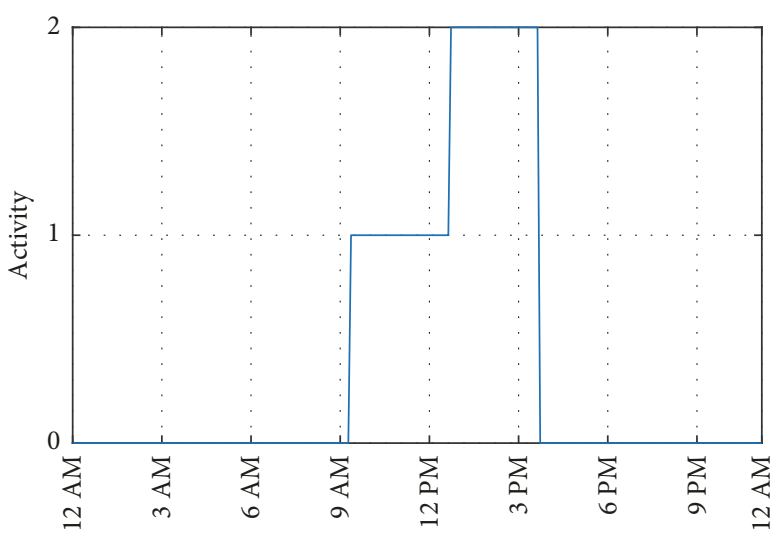

(c) User ID: $219161(2 / 13 / 2015)$

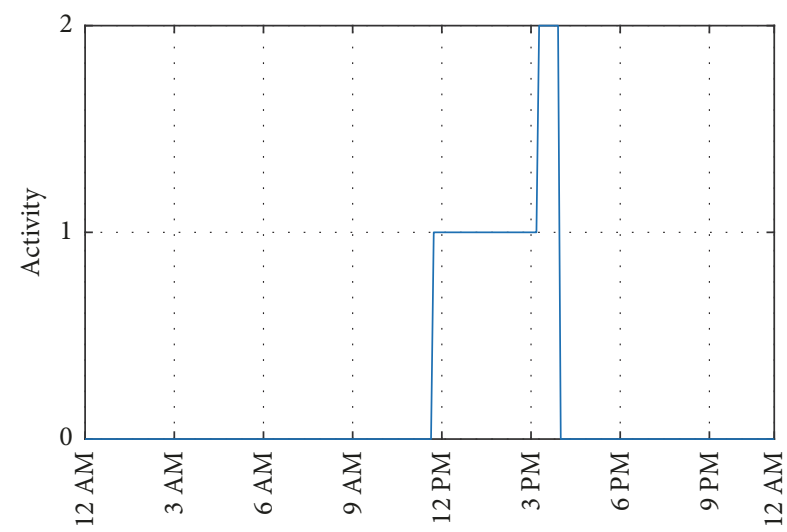

(b) User ID: 137113 (4/15/2015)

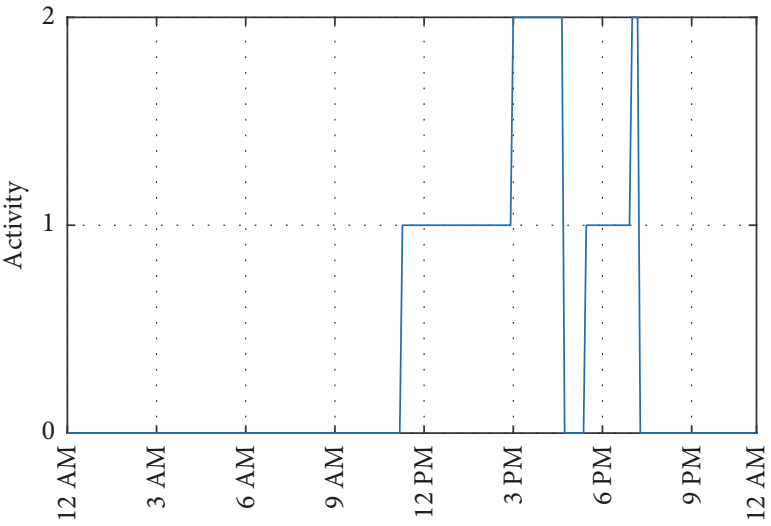

(d) User ID: 219161 (3/10/2016)

FIGURE 2: Observed charging patterns of PEV drivers in the sample (“0"—no activity, "1"—charging, and "2"—parking without charging).

TABLE 1: Land use around public charging stations $[25,26]$ (for $1 / 4$ mile radius).

\begin{tabular}{lccc}
\hline & $\begin{array}{c}\text { Rochester Downtown } \\
\text { (RDT) }\end{array}$ & $\begin{array}{c}\text { Marketview Heights } \\
(\text { MVH })\end{array}$ & $\begin{array}{c}\text { Ontario Beach Park } \\
(\text { OBP })\end{array}$ \\
\hline Population density (per sq. mile) & 6200 & 7700 & 3500 \\
Unemployment rate & $11 \%$ & $26 \%$ & $7 \%$ \\
Residential land use & $4 \%$ & $38 \%$ & $34 \%$ \\
Commercial land use & $58 \%$ & $31 \%$ & $7 \%$ \\
\hline
\end{tabular}

Corporation [22] and can be considered as a business district with $58 \%$ (Table 1) of the land use around the charging stations is occupied for commercial use. The MVH is defined by the area defined in the Rochester Public Market Master Plan Report prepared by Market Ventures Inc. for the City of Rochester in February 2012 [23]. The MVH area has 31\% occupancy for commercial use and $38 \%$ for residential use. Further, the OBP encompasses the areas as defined by Monroe County Parks Department [24], and 34\% of properties around the area are occupied for residential use. Given these guidelines, five stations are located within the RDT area, and one station is located at each of the MVH and OBP extents. Figure 1 shows the locations of charging stations and Table 1 shows the land use of the neighborhood around these public charging stations. The figure marks the locations of charging stations and not actual number of charging stations. For example, a map of parking lots marks locations parking lots and not the capacity of total number of vehicles the lots can accommodate. Similarly, Figure 1 depicts the seven locations of charging stations. Therefore, each location may contain more than one charging station and can accommodate at least two vehicles at a time. Further, Table 2 summarizes data from the charging stations at these locations.

2.1. Data Processing. The unit for this pattern analysis was one daily PEV charging pattern for a single vehicle observed at public charging stations. Consequently, drivers who used the stations on multiple days had multiple daily patterns in the sample considered for analysis. PEVs reside in one of three 


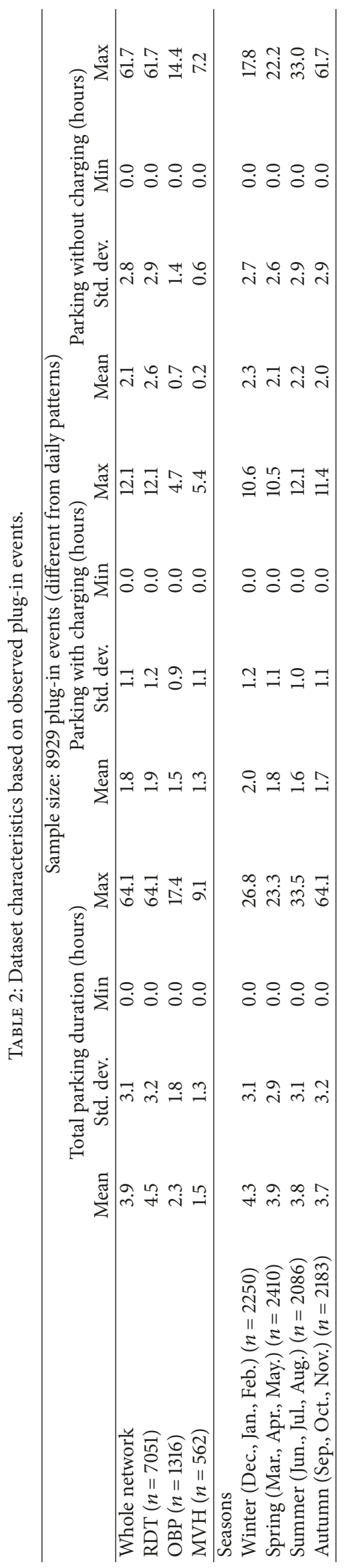


states: (i) not parked (no activity); (ii) parked with charging; and (iii) parked without charging, each assigned a numerical value of 0,1 , or 2 , respectively. Since only a nominal scale for activities is required for pattern analysis and classification, the actual values of each state are inconsequential. Examples of observed charging patterns are shown in Figure 2. The resulting daily pattern was further discretized into 256 data points taken at 5.625-minute intervals. The final resolution (number of points) is bounded by the requirements of the Walsh-Hadamard Transform [27] used in the pattern analysis, which requires the number of data points $(n)$ to be of the order of $2^{n}$.

Errors in the logged data led to incomplete observations which were omitted from analysis. Charging events that contained total parking durations of two minutes or less were also omitted as these events are from the user (a) opening a charging session without inserting the plug into their car and then the system automatically closes the session to allow other users to use the station, or (b) the original user opens a session and decides to switch charging to an alternate port at the station (these causes were confirmed by the ChargePoint help desk staff). Events with missing or zero station user IDs were also omitted. The original dataset contained a total of 9,680 unique charging events between March 2014 and May 2016. After omitting these events based on previously stated criteria, 8,929 unique charging events were used for subsequent analysis. Using these 8,929 unique charging events, 7,554 unique daily charging patterns were generated by "stitching them together" for a particular vehicle and day for the pattern analysis.

\section{Methodological Approach}

In order to characterize the daily PEV charging patterns of drivers, a pattern analysis is applied to identify homogenous segments or clusters of patterns. Charging patterns are quite complex, varying over time and geography. Example patterns observed in the sample are given in Figure 2. Each of these patterns represents a daily profile that starts at 12:00 AM and ends at 11:59 PM (24-hour period) for a particular PEV driver. For example, the first pattern (a) (User ID: 137113) shows that the driver started his/her activity around 7:30 AM and used the facility for charging until 10 AM and continued to park without charging until 3:30 PM. This PEV driver, thus, used the facility for 8 hours but charged the PEV for only 2.5 hours. Daily patterns can also consist of multiple charging events. Pattern (d) shows a PEV driver using the station twice (two plug-in events) in a single day. In the case of multiple plug-in events within a single day ( 24 hours) for the same PEV driver, events were stitched together into a single daily charging pattern. In pattern (d), the driver used the station for charging for a total of 5.5 hours out of 7.25 hours of parking.

Given the complexity and time-varying nature of PEV charging patterns, a pattern analysis helps identify clusters of similar patterns to facilitate discussion and subsequent analysis. Apart from uncovering similarities across patterns, this approach can also simplify and summarize a large sample of pattern data. Past studies use pattern analysis to classify travel patterns [28] and characterize vehicle travel patterns and to examine the feasibility of PEV operation [29]. This study adopts a similar approach towards classifying daily charging patterns of PEV drivers into homogenous segments with respect to their daily patterns.

Pattern analysis has been applied to a wide range of fields from voice recognition to image analysis, all of which aim to classify patterns into sensible segments. The clusters do not group the PEV users but the daily charging profiles of the PEV users observed at the public charging stations. The same PEV user can have multiple patterns of usage and can be observed to use the charging stations at different locations. Importantly, pattern analysis can provide different and a few in number clusters of homogeneous daily charging profiles, and the identified clusters can be used for policy making where a particular charging behavior can be targeted. Furthermore, the observed operational inefficiency depends on the patterns of charging behavior, and along with the total parking without charging time, it is important to understand how this inefficiency is distributed. The pattern analysis provides the specific number of clusters of daily profiles which can further understand the causes of the operational inefficiency.

The overall methodological framework is shown in Figure 3. Conventionally, a sequential three-stage process of pattern analysis consists of (i) pattern specification, (ii) feature extraction, and (iii) clustering. First, plug-in event data is taken from the sample and stitched together to form daily patterns. The process for this was described previously in Section 2. Given the resulting sample of daily charging patterns, features are extracted from these daily patterns for the subsequent clustering stage. The output of clustering and consequently the entire pattern analysis process is a set of homogenous segments of patterns, with patterns within the same segment being similar to each other, while patterns in different segments are dissimilar to patterns in other segments. These identified segments serve as the basis for subsequent scenario analysis to investigate the potential of policy interventions and technology options. The next section describes the pattern analysis process and discusses the clusters that are an outcome of this process.

3.1. Pattern Analysis Process. Conventionally, pattern analysis consists of a sequential three-stage process: (i) pattern specification, (ii) feature extraction, and (iii) clustering. These stages and the overall methodological framework are described further in the next section.

3.1.1. Pattern Specification. First, plug-in event data are taken from the sample and stitched together to form daily patterns. In this stage, all the plug-in events are converted into a "signal" consisting of three possible states that refer to three activities, "0" for no activity, "1" for charging activity, and " 2 " for parking without charging activity, as explained in the previous section. Daily time-varying EV charging patterns are generated or "stitched" together in chronological order based on the timestamp of charging events logged by the 


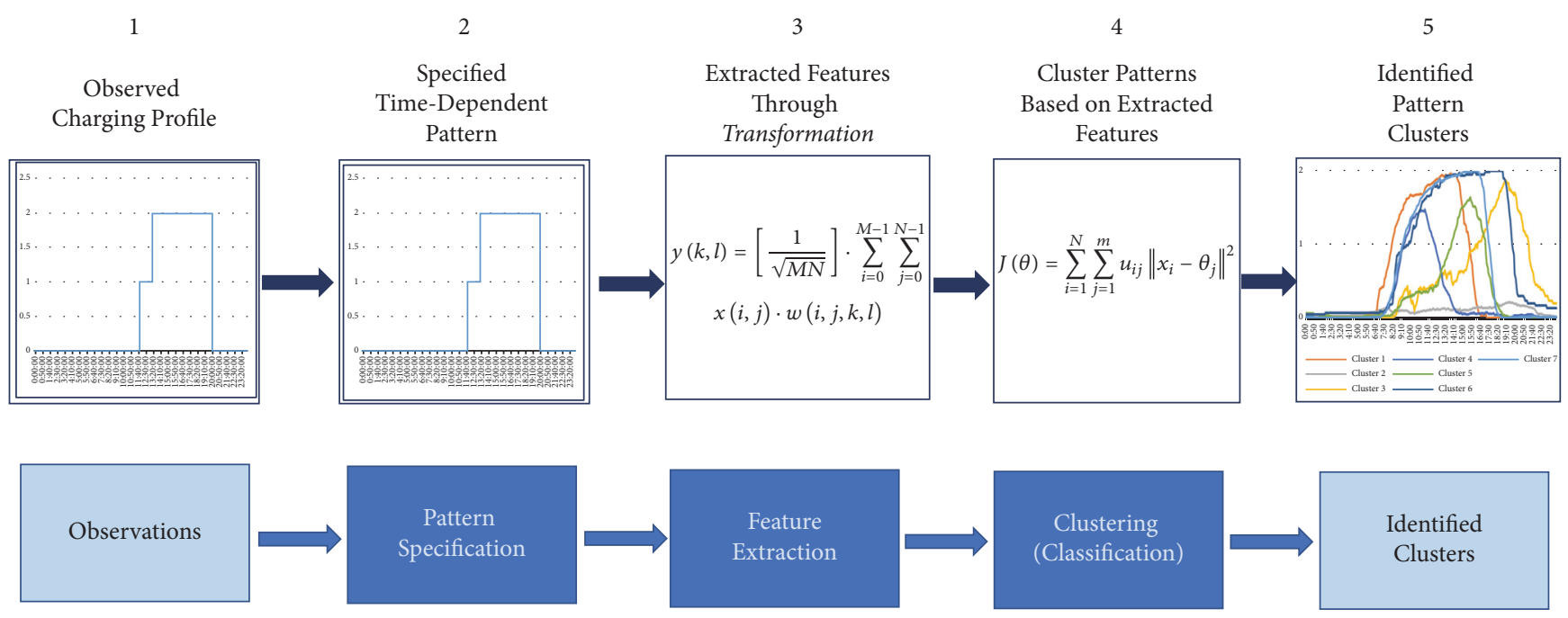

Figure 3: Methodological framework.

smart charging stations. Examples of patterns specified and outputted in this stage were shown in Figure 2.

3.1.2. Feature Extraction. In this stage, features are extracted from the specified patterns for subsequent clustering. Observed events such as charging (state $=1$ ) and parking without charging (state $=2$ ) are time-dependent. The main goal of feature extraction is to extract statistically independent "features" from the observed patterns that are best suited for subsequent cluster analysis in the classification stage. These features serve to summarize the patterns and capture the most important pattern characteristics. The feature extractor used is the Walsh-Hadamard Transformation (WHT), though others such as the Karhunen-Loeve or Haar could also have been used [27]. The WHT extracts features referred to as Walsh coefficients [29] that are used in the cluster analysis. These extracted features can conceptually be considered as "building blocks" of the observed patterns. An analogous process would be a principle components analysis on a digital image. In pattern analysis, a feature extraction allows identifying separate orthogonal features from the image, or in this case time-dependent pattern. These features, in this case Walsh coefficients, are used in subsequent clustering of patterns as "attributes" of this observed pattern.

3.1.3. Pattern Classification. The extracted features from the previous stage are used in a clustering algorithm to identify homogenous segments of patterns. The output of clustering and consequently the entire pattern analysis process is a set of pattern segments, with patterns within the same segment being similar or homogenous to each other, while patterns in different clusters are dissimilar to each other. Conceptually, each cluster contains patterns (which are timedependent) that have similar "features." In the literature, several clustering algorithms exist; this study uses the $k$ means clustering algorithm.

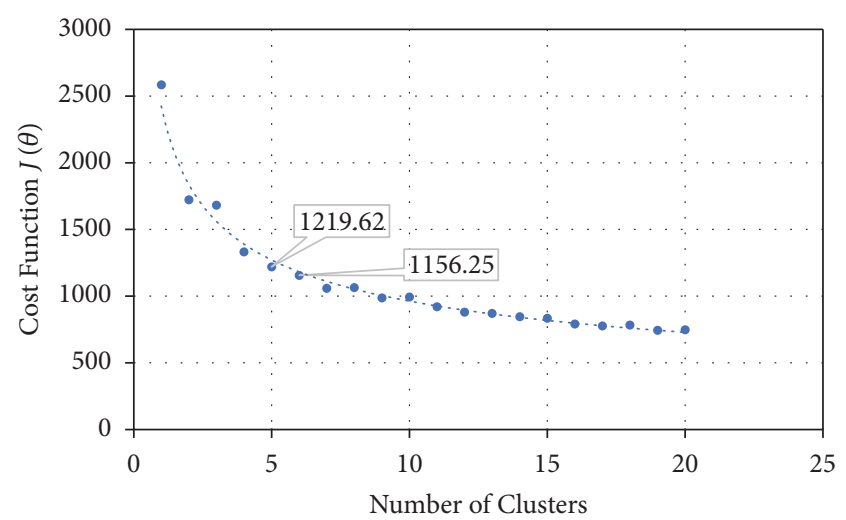

FIGURE 4: Cost function value versus number of clusters assumed a priori.

The $k$-means algorithm is a cost-based algorithm [30], in which the cost function $J(\theta)$ is given by

$$
J(\theta)=\sum_{i=1}^{N} \sum_{j=1}^{k} u_{i j}\left\|x_{i}-\theta_{j}\right\|^{2},
$$

where $\theta_{j}$ is the centroid of cluster $j, u_{i j}$ is a binary indicator that equals 1 if point $x_{i}$ is nearest to $\theta_{j}, N$ is the total number of points, and $k$ is the number of clusters. For the $k$-means algorithm, the number of clusters is specified a priori. As the number of clusters increases the marginal reduction in the cost function decreases until a negligible value, indicating the correct number of clusters, is specified. A plot of the cost function $(J(\theta))$ as a function of number of clusters $(k)$ is given in Figure 4. It shows the variation of cost function with respect to increasing number of clusters. The final number of clusters for a particular sample of patterns is determined based on identifying the point of marginal return on the cost function. 


\section{Identified Clusters of Daily Charging Profiles}

The pattern analysis approach described in the previous section identified 5 distinct clusters of daily charging profiles from the sample. This section examines the clusters and their members with respect to (i) charging, (ii) parking without charging, and (iii) parking durations. Additionally, inverse Walsh-Hadamard Transform on the feature centroids of each cluster is used to reconstruct a composite image for each cluster and to facilitate interpretation. These images are shown in Figure 5.

4.1. Characterization of Identified Clusters. Each identified cluster is characterized with respect to charging and parking activities. Figure 5 shows the reconstructed profiles from the inverse Walsh-Hadamard for each cluster. Note that the profile represents a composite of all activities at a specific time. For example, only if all events at a specific time were charging ( state $=1$ ) would the profile distinctly indicates "charging." For this reason, the distribution of patterns within each cluster residing in the three different states considered is also plotted over the one-day period.

4.1.1. Cluster 1 (CL-1, 772 Patterns; 10\% of the Samples of Patterns). The reconstructed composite profile of CL-1 indicates that most charging activities start at 6:30 AM and peak ( $60 \%$ of patterns) at 8:45 AM. The daily profiles in this cluster are observed to have a peak ( $90 \%$ patterns) of parking without charging activity at about 1:45 PM. The patterns from CL-1 are mostly (85\%) observed at RDT on weekdays $(95 \%)$.

4.1.2. Cluster 2 (CL-2, 3,438 Patterns; 46\% of the Samples of Patterns). The composite profile of CL-2 has a distribution characterized by a low peak (20\% of events) at 2:15 PM. Note again that the profile represents a composite of all activities at a specific time, making it difficult to tease out specific activities. The peak of parking without charging activity is observed at 3:30 PM with only $12 \%$ of patterns. Unlike CL1 , the patterns from CL-2 are observed at all the locations and have the highest $(30 \%)$ contribution of patterns observed on weekends. The patterns observed at MVH have the highest contribution of $14 \%$ in CL-2 compared to the rest of the clusters. As CL-2 is largely comprised of shorter plug-in events, and, by MVH being the location near a public market, it can be inferred that the PEV drivers who access the public charging stations at the $\mathrm{MVH}$ and have charging profiles belonging to the CL-2 tend to use the charging stations for shorter durations.

4.1.3. Cluster 3 (CL-3, 1,355 Daily Patterns; 18\% of the Samples of Patterns). These patterns show a peak (68\%) of charging activity at 8:45 AM and a very high level of parking without charging activity with a peak $(98.45 \%$ of patterns) at 4:15 PM. The patterns in this cluster indicate more parking without charging than parking with charging. CL-3 is constituted of $98 \%$ patterns observed at RDT and $97 \%$ patterns observed on weekdays. Similar to CL1 , the charging activity of such patterns coincides with a typical working day schedule around the business district of Rochester.

4.1.4. Cluster 4 (CL-4, 1,500 Patterns; 20\% of the Samples of Patterns). The parking with charging activity for these patterns peaks (70\% of patterns) at 9:00 AM. The parking without charging activities peaks ( $60 \%$ of patterns) at 11:30 AM. CL-4 does not have higher peak of parking without charging activity than parking with charging activity. Further, the patterns observed at RDT are $84 \%$ and $92 \%$ are observed on weekdays.

4.1.5. Cluster 5 (CL-5, 489 Patterns; 6\% of the Samples of Patterns). The parking with charging of these patterns peaks (55\% of patterns) at 9:00 AM. The parking without charging peaks (90\% of patterns) at 5:30 PM. The patterns observed at OBP have the highest contribution of $27 \%$ in CL-5 compared to the rest of the clusters. As OBP can be considered as a leisure place, a typical PEV driver may stay at OBP for the entire day, which can be inferred with the charging activity ranging from 7:30 AM to 6:20 $\mathrm{PM}$.

Importantly, the charging profiles observed in CL-3, CL1, and CL-5 show charging behavior characteristics which are likely to be observed on a working day at a public charging station located in business district, in this case RDT.

4.2. Comparison of Identified Clusters. Figure 6 shows distribution of three dimensions, across patterns within each identified cluster: (a) parking duration (PD), (b) parking duration with charging (PDWC), (c) parking duration without charging (PDWOC), and (d) total sum of parking without charging durations of all patterns across different clusters. For PD, CL-5 while being the smallest cluster with only 489 daily patterns, had the highest median PD (more than 10 hours). However, CL-2, the largest cluster with 3,438 daily patterns, has the lowest median PD (2 hours). Irrespective of the cluster sizes, the median for PD varies from 2 hours to 10 hours. In contrast, the PDWC does not vary significantly across clusters. The median for PDWC varies from 1.5 hours to 2.5 hours across clusters. Figure 6(c) also shows the distribution of PDWOC for all clusters. CL-5 has the highest median around 7.5 hours and CL-2 has the lowest (almost negligible) median. This characteristic of a charging behavior indicates efficient (or inefficient) operation of charging stations. Furthermore, Figure 6(d) shows that CL-3 has the highest total sum duration of hours spent parking without charging, followed by CL-1 and CL-5. These total hours spent parking without charging activity indicate the inefficiency of user turnaround at stations, likely due to the currently cost-free situation. Figure 6 also shows that, except for CL-2 and CL-4, the remaining clusters exhibit a higher median for PDWOC, relative to PDWC. However, due to their membership sizes, CL-2 and CL-4 still show a significant total sum duration of parking without charging. 


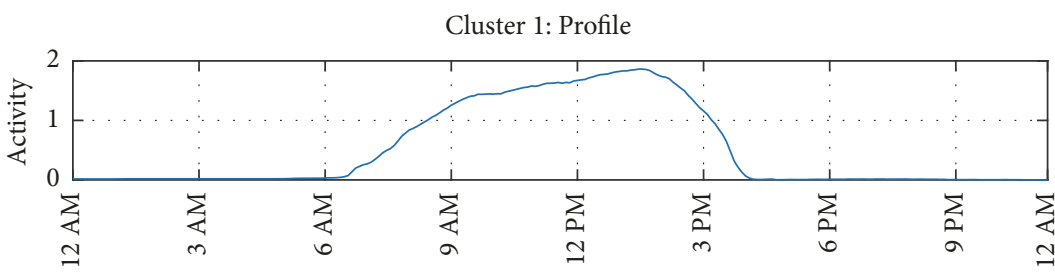

Cluster 1: No Activity

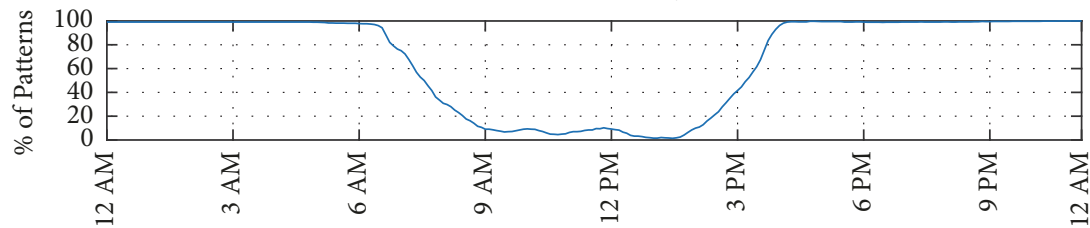

Cluster 1: Charging Activity

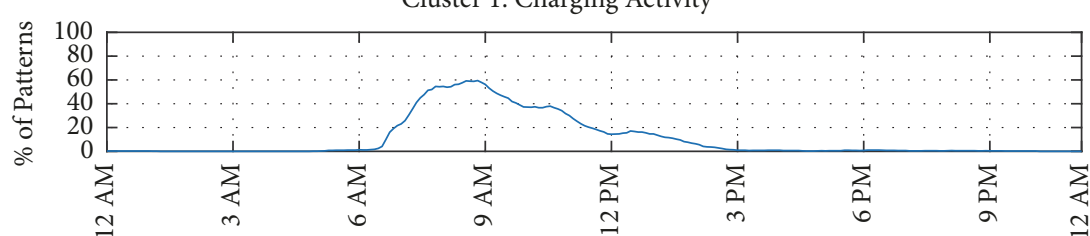

Cluster 1: Parking Without Charging Activity

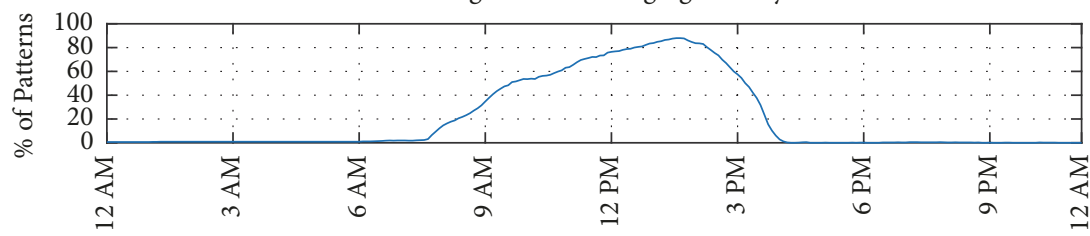

(a)

Cluster 2: Profile

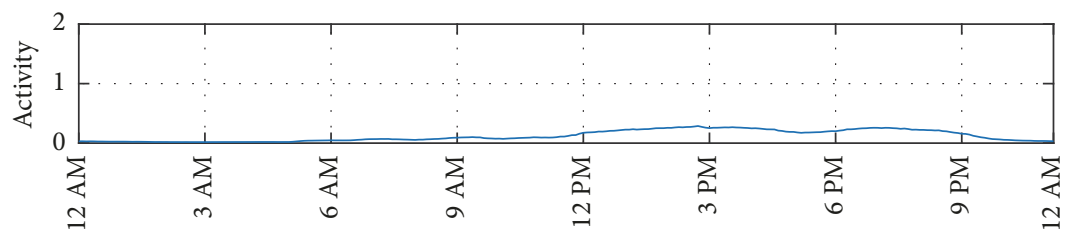

Cluster 2: No Activity

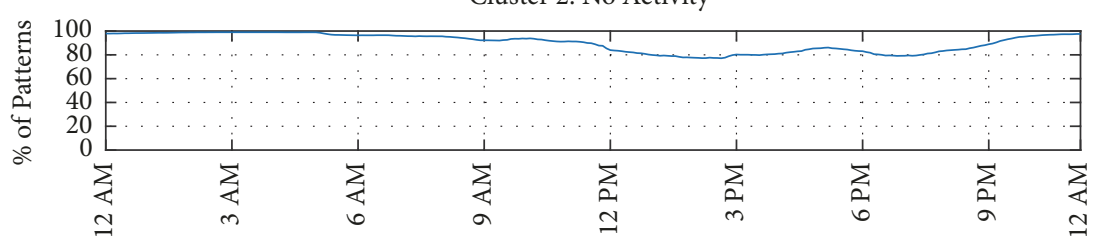

Cluster 2: Charging Activity

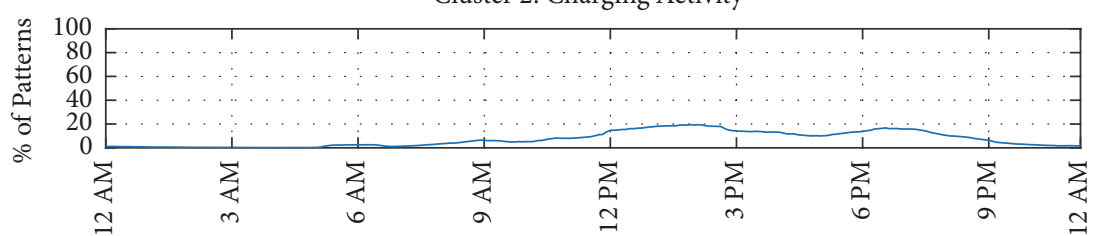

Cluster 2: Parking Without Charging Activity

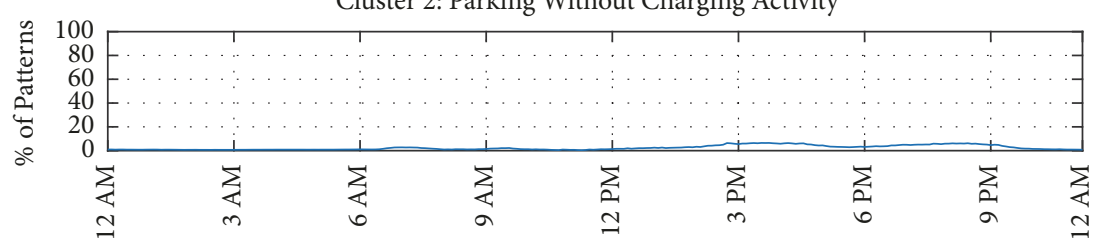

(b)

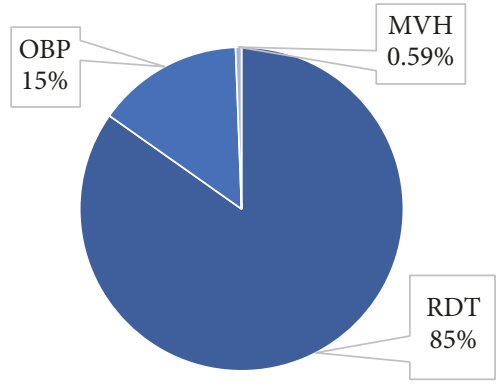

"RDT" - Rochester Downtown "OBP"- Ontario Beach Park

"MVH" - Marketview Heights
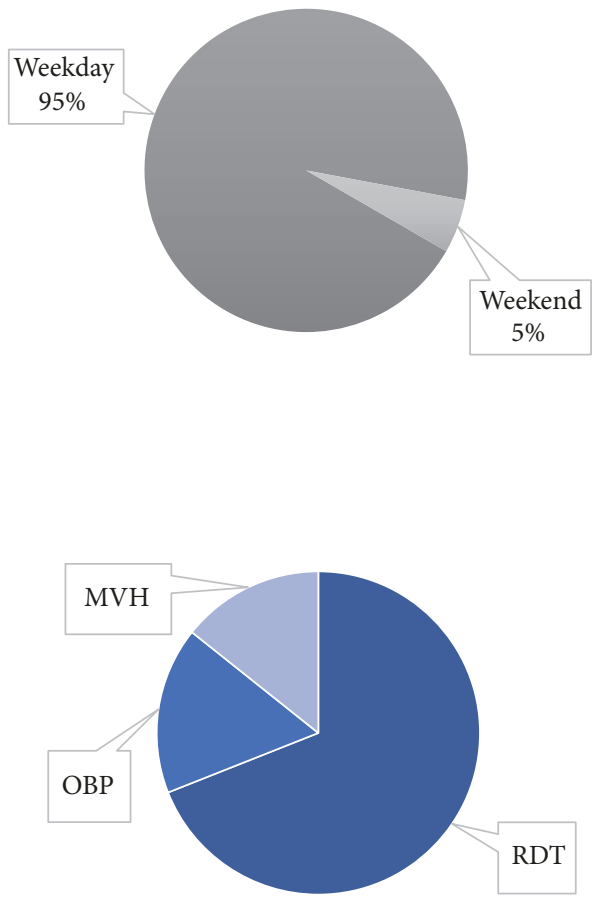

"RDT" - Rochester Downtown "OBP"- Ontario Beach Park

"MVH" - Marketview Heights

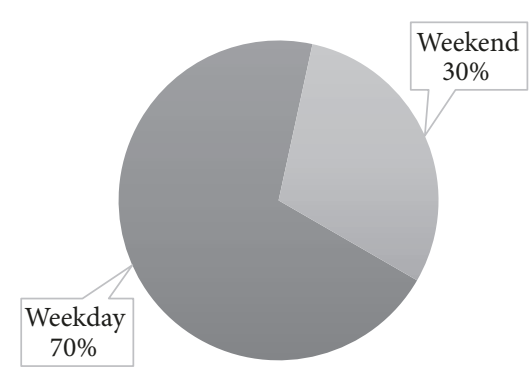

FIGURE 5: Continued. 


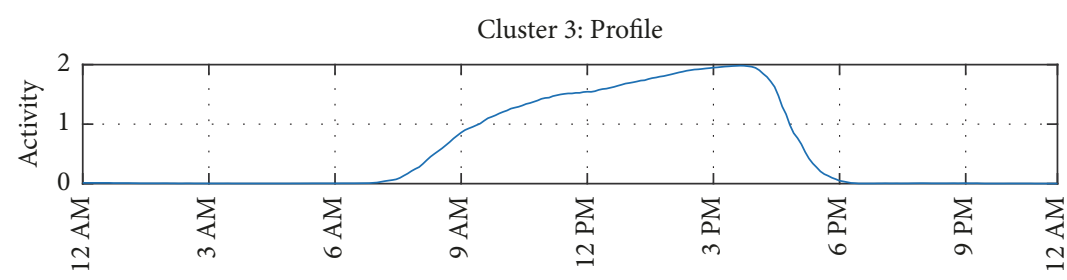

Cluster 3: No Activity

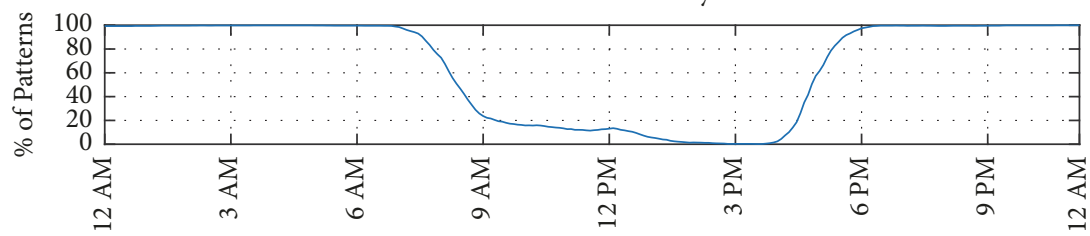

Cluster 3: Charging Activity

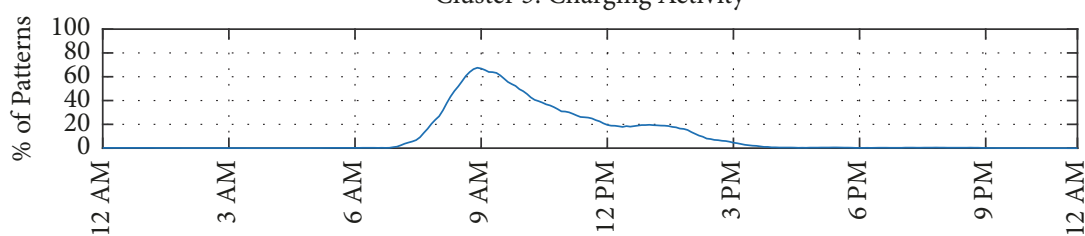

Cluster 3: Parking Without Charging Activity

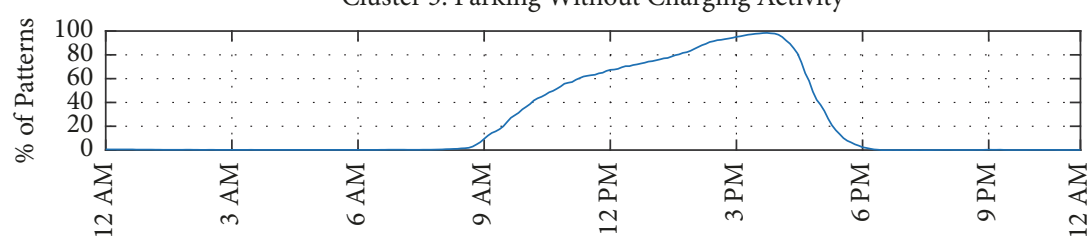

(c)

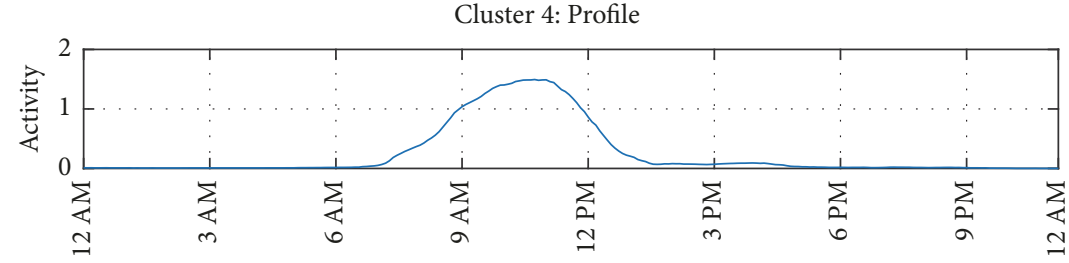

Cluster 4: No Activity

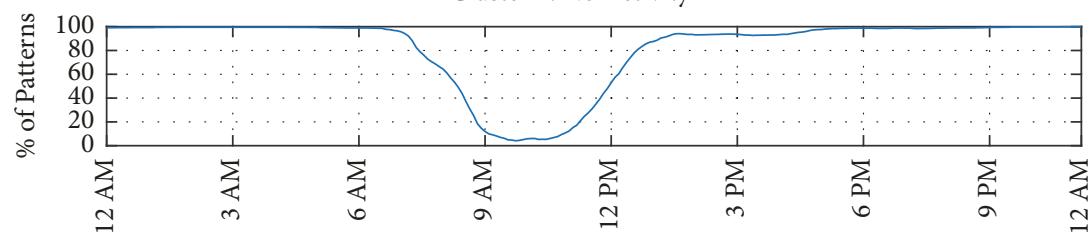

Cluster 4: Charging Activity

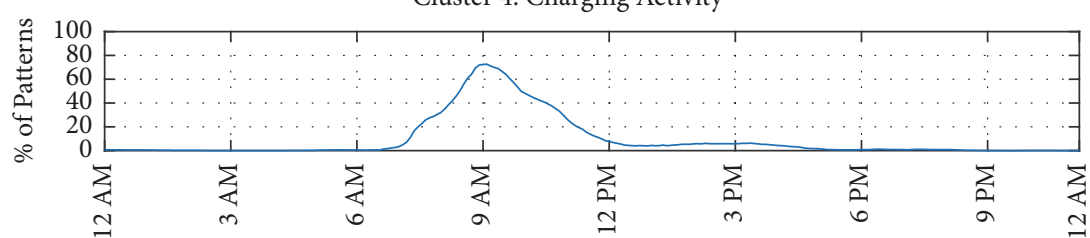

Cluster 4: Parking Without Charging Activity

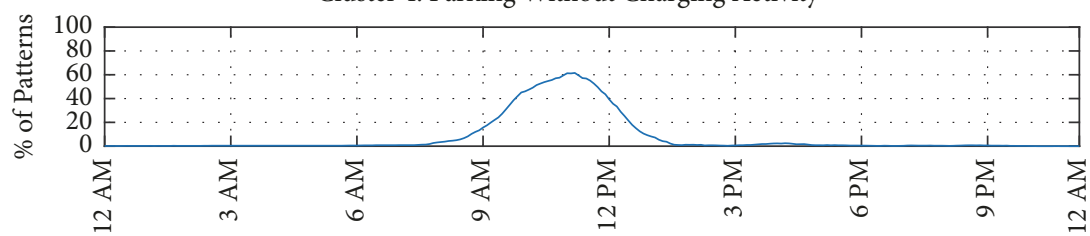

(d)

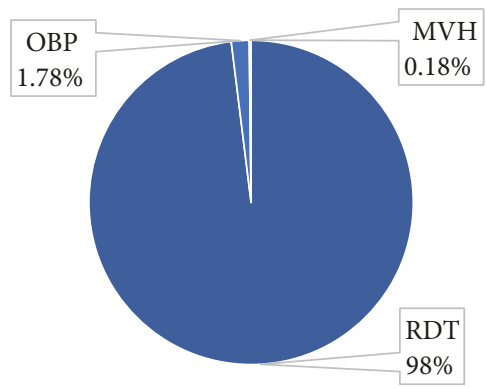

"RDT" - Rochester Downtown "OBP"- Ontario Beach Park

"MVH" - Marketview Heights
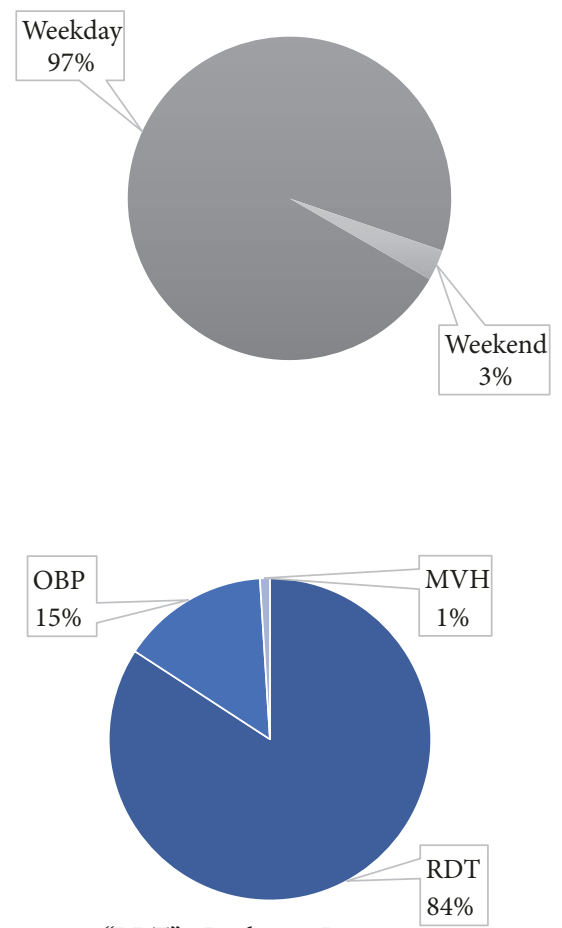

"RDT" - Rochester Downtown "OBP"- Ontario Beach Park

"MVH" - Marketview Heights

Weekday $92 \%$

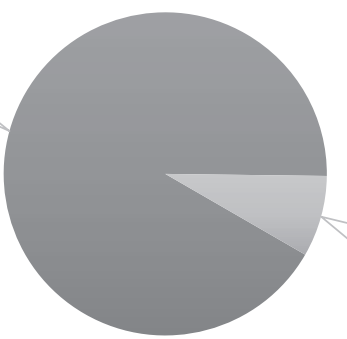

Weekend $8 \%$

Figure 5: Continued. 

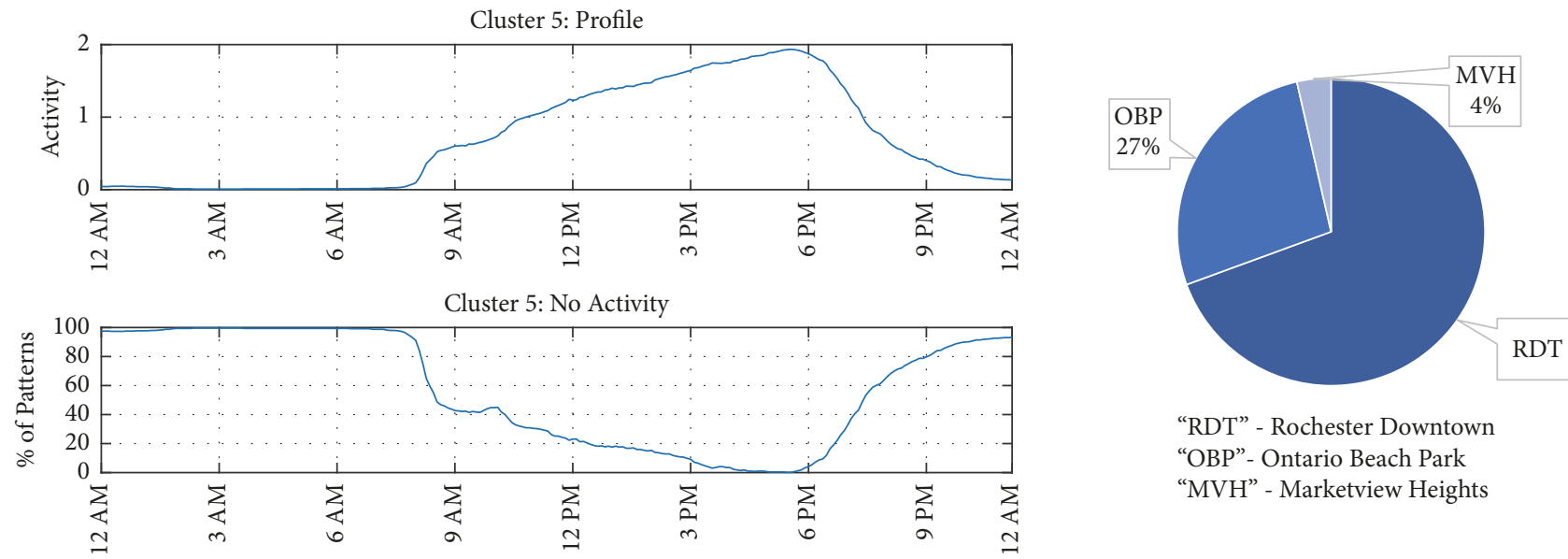

"RDT" - Rochester Downtown "OBP"- Ontario Beach Park "MVH" - Marketview Heights

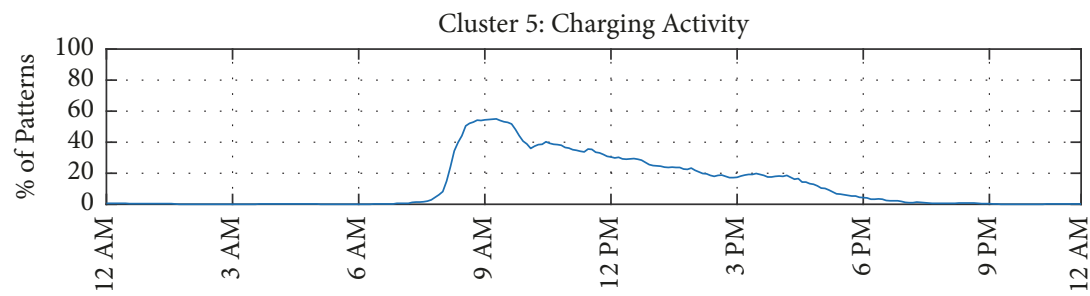

Cluster 5: Parking Without Charging Activity
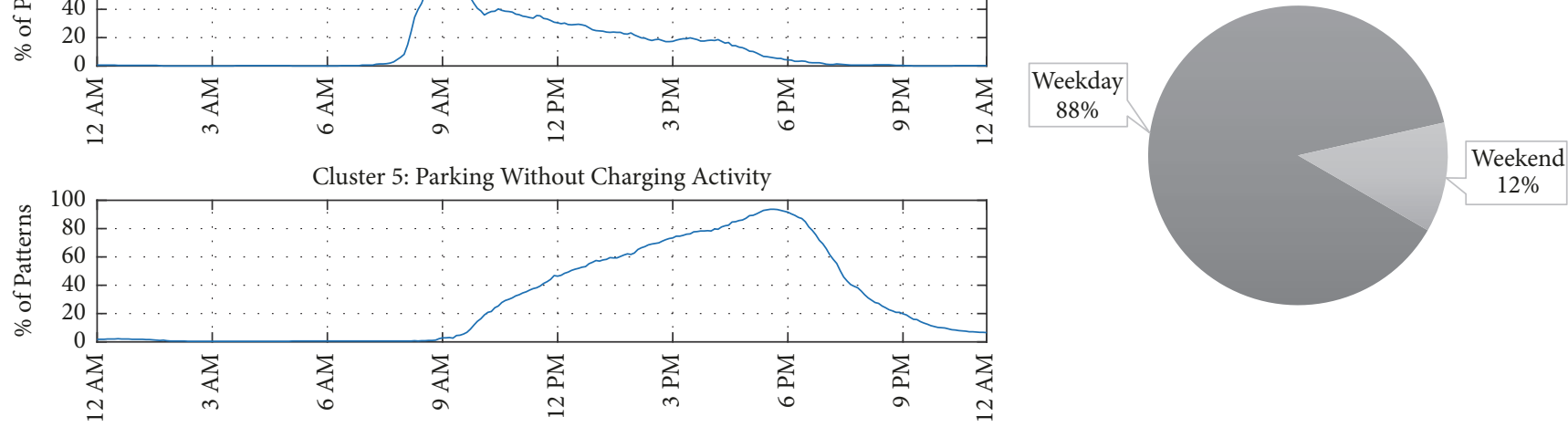

(e)

FiguRE 5: Cluster profiles and distribution of patterns in activities " 0 " - no activity, "1" - parking with charging, and "2" - parking without charging along with distribution of patterns with respect to location and type of day the pattern was observed (e.g., weekday of weekend) (a) Cluster 1, (b) Cluster 2, (c) Cluster 3, (d) Cluster 4, and (e) Cluster 5.

\section{GHG Emissions Analysis}

The pattern analysis in the previous section uncovered five distinct clusters of daily charging profiles, each with a large frequency and total sum duration of parking without charging across daily profiles of PEV drivers. User operational inefficiency at charging stations is an issue that needs to be addressed to efficiently allocate institutional resources. Additionally, this inefficiency may demotivate potential PEV adopters who see out-of-home charging locations constantly occupied.
This scenario examines the impact of reducing inefficient station use through reducing the parking without charging duration. By allowing more efficient use and turnaround of charging stations, more PEV drivers can use the stations, thus potentially displacing gasoline miles incurred otherwise with electricity. These drivers could be potential PEV adopters or current PEV drivers who see the occupied station and turn away discouraged. The main assumption is that $100 \%$ time spent in parking without charging can be replaced with PEV drivers who need to charge. The GHG emissions savings from this displacement of inefficient station sue are determined as follows:

GHG Emissions Savings = Emissions displaced by replacing gasoline

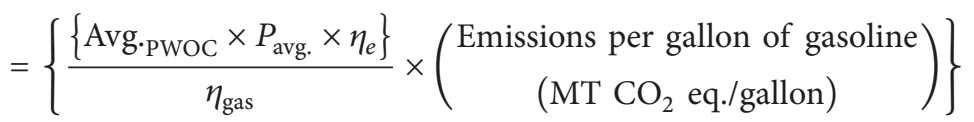

$$
\begin{aligned}
& -\left\{E \times\left(\begin{array}{c}
\text { Emissions per } 1 \mathrm{kWh} \text { of electricity generation in NYUP } \\
\left(\mathrm{MT} \mathrm{CO}_{2} \text { eq./kWh }\right)
\end{array}\right)\right\} \text {, }
\end{aligned}
$$




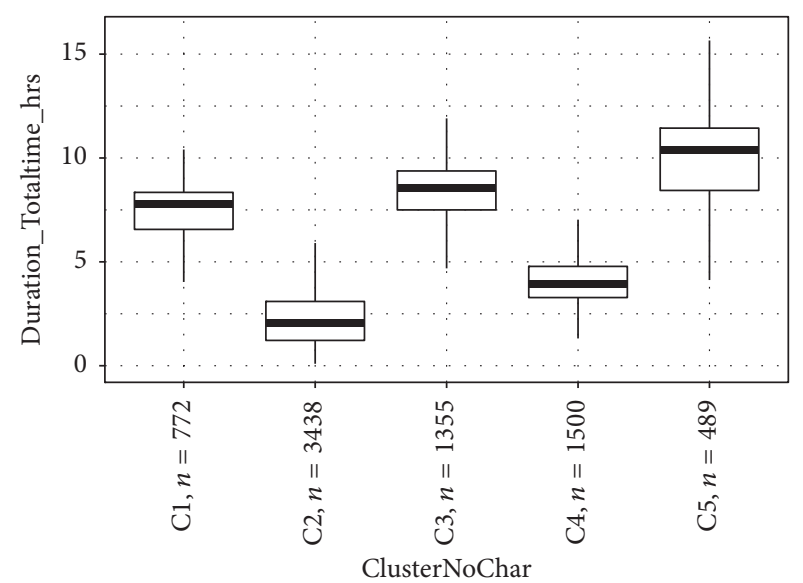

(a) Total parking duration (clusters)

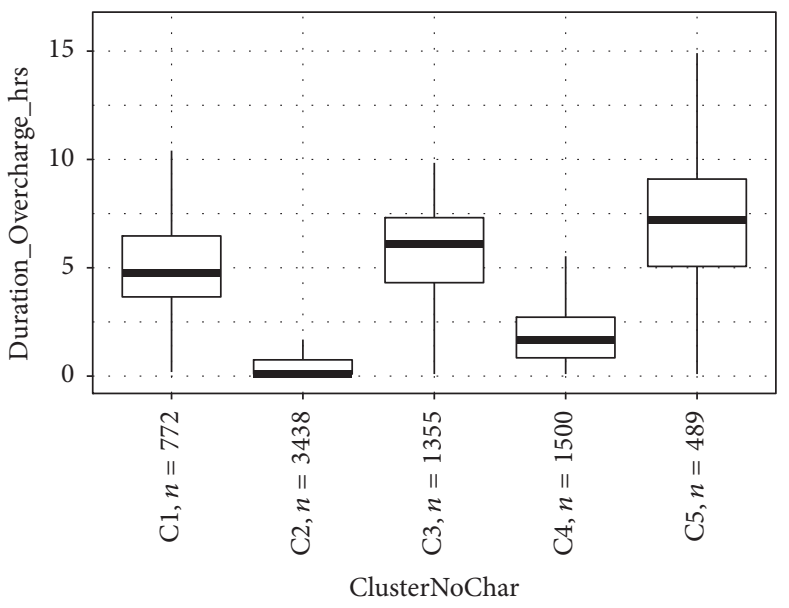

(c) Total parking duration w/o charging (clusters)

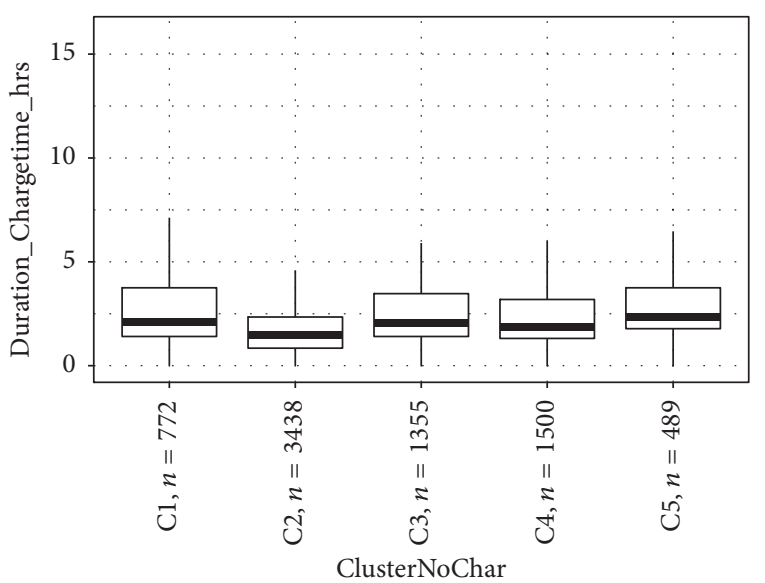

(b) Total parking duration w/ charging (clusters)

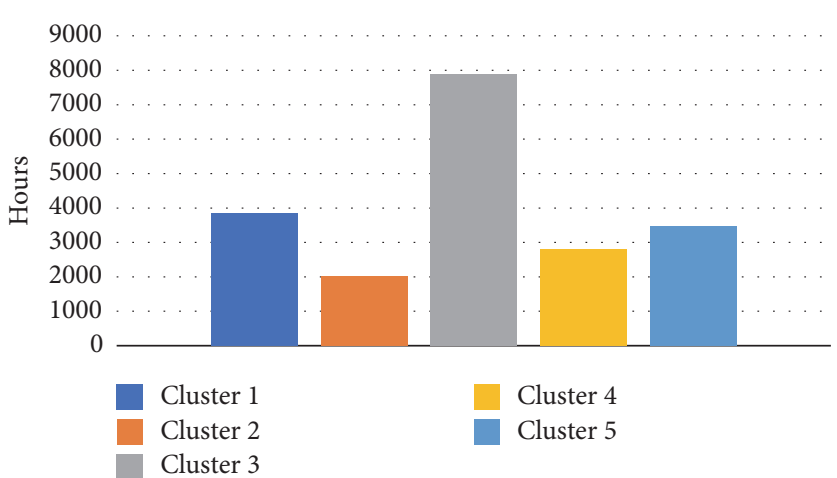

(d) Total hours of parking w/o charging

FIGURE 6: Variation of activities across clusters: (a) parking duration (hours), (b) parking duration with charging (hours), (c) parking duration without charging (hours), and (d) total (i.e., sum of all the daily patterns in the respective cluster). Hours of parking without charging across clusters.

where Avg.Pwoc is the average time spent in parking without charging in hours per daily profile in respective cluster, $P_{\text {avg. }}$ is the assumed average charging rate of $3 \mathrm{~kW}$, which is averaged rate across all the individual plug-in events in the observed sample in $(\mathrm{kW})$, and $\eta_{e}$ is the electrical efficiency of PEVs in (miles/kWh) and is assumed based on the literature: 3 miles/kWh [31] —for increase and decrease in electrical efficiency, the GHG emissions savings vary in proportion and $E$ is electricity consumed per average profile of respective cluster in $(\mathrm{kWh})$. Given that consumption of 1 gallon of gasoline emits $8.887 \times 10^{-3}$ metric tons (MT) of $\mathrm{CO}_{2}$ eq. [32] - for gasoline, $\mathrm{CO}_{2}$ and $\mathrm{CO}_{2}$ equivalent being the same because gasoline combustion results in only $\mathrm{CO}_{2}$ and $\mathrm{H}_{2} \mathrm{O}$ - the total GHG emissions displaced by allowing more station charging can be calculated. The analysis was carried out for each individual cluster identified.

To determine the GHG emissions from the electricity consumed, hourly electricity consumption is assumed to correspond to the number of PEV drivers using the facility for charging at that particular hour. Additionally, for upstate New York, the electricity production mix changes at each hour depending upon the demand for electricity [33], resulting in varying environmental impact each hour per $\mathrm{kW}$-hr of charge. Figure 7 depicts the global warming potential (GWP) in terms of $\mathrm{kg}$ of $\mathrm{CO}_{2}$ equivalent for one unit $(1 \mathrm{kWh})$ of electricity production for a varying grid mix of upstate New York [32] for a typical day.

Figure 7 shows that every $1 \mathrm{kWh}$ of electricity produced from 12:00 AM until 8:00 AM is cleaner compared to the rest of the day and the GWP stays below $0.5 \mathrm{~kg}$ of $\mathrm{CO}_{2}$ equivalent. However, after 8:00 AM, the GWP of electricity production starts increasing and around 6:00 PM it has the highest GWP of $0.56 \mathrm{~kg}$ of $\mathrm{CO}_{2}$ eq. because at this hour the electricity grid mix has most of the supply from fossil fuel power plants to meet the additional peak demand. Therefore, every $1 \mathrm{kWh}$ of electricity consumed by the PEV drivers during a day has GWP directly proportional to the GWP shown in Figure 7 at that hour. Figure 7 further shows the GHG emissions for 


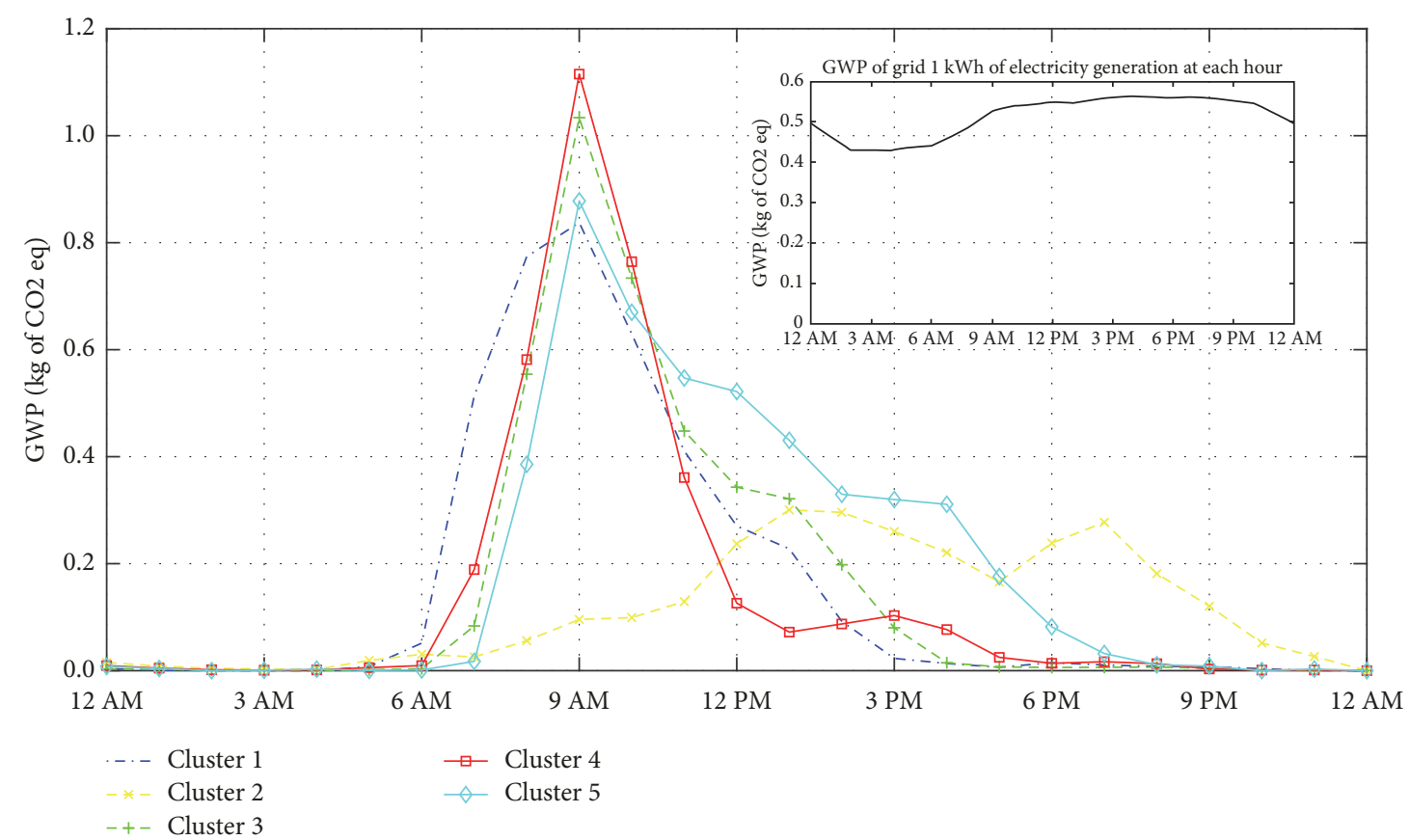

FIGURE 7: Global warming potential (GWP) in terms of $\mathrm{kg}_{\mathrm{G}} \mathrm{CO}_{2}$ eq. for electricity consumed by an average daily profile of respective cluster at each hour and emissions from grid for generation of $1 \mathrm{kWh}$ at each hour.

an average profile belonging to each cluster. CL-4 at 9:00 AM shows the highest GHG emissions, followed by CL-3 and CL5 , respectively. Note this peak occurs at a specific time.

Looking at average daily profiles for each cluster and their GHG emissions savings indicate opportunities for significant emissions savings. Overall, if efficiency in PEV user operations is improved, that is, the PDWOC is reduced, significant GHG emissions savings can be realized. For an average daily profile, CL-5 has the maximum total GHG emissions savings potential across the day, largely because profiles in this cluster have the highest average parking without charging time over the day. CL-3 and CL-1 have the second and the third largest GHG emissions savings potential for similar reasons based on the entire daily GHG savings. Finally, CL-2 has the least GHG emission savings, due to low PDWOC, over the day, relative to the other clusters (Figure 6(c)). Overall, the results suggest that displacing inefficient parking at charging stations with PEV charging from additional PEVs can lead to significant GHG emission savings, even in the case of CL-2 which has a lower median of PDWOC relative to the other clusters.

As stated earlier, in Section 4.2, the CL-3 has the highest PDWOC (Figure 6(d)), with respect to the sum of all the daily charging profile in the cluster; proportionately this cluster has 7880 hours of total parking without charging duration, which is the highest among all five clusters. However, a daily charging profile belonging to CL-5 exhibits the longest PWOC activity (starting at 9:00 AM until 12:00 AM, shown in Figure 5(e)). This can also be referred to in Figure 5(c); CL-5 has the highest median of PDWOC per daily profile, followed by CL-1 and CL-3, respectively. If all the clusters were of the same membership size, the CL- 5 would have had the largest total parking duration without charging and hence the maximum GHG emissions savings potential. If the hourspecific electricity consumption is considered as a criterion, a CL-4 profile has the highest GHG emissions at 9:00 AM (Figure 7), followed by CL-3 and CL-5, respectively, which corresponds to the charging activity of an average profile belonging to a particular cluster at 9:00 AM.

As this dataset sample may not represent the actual population of charging events, we cannot draw inferences at the population level. However, based on this sample, for realizing GHG emissions savings, we can target the daily profile represented in CL-5, as they exhibit the highest PDWOC on a typical day, or we can target the daily profile represented in CL-3, as the CL-3 has the highest total parking without charging duration (in total hours). If the calculations of GHG savings are performed considering efficiency of gasoline vehicles, with respect to the projections of expected improvements in miles per gallon (mpg) as per CAFE standards [34], the amount of GHG emissions displaced varies in proportion to the gasoline vehicle efficiencies. For higher gasoline engine efficiency, the emission savings are less and vice versa.

\section{Conclusion}

Our results indicate that the daily charging profiles of PEV drivers observed at the public charging stations can be clustered into five different groups based on their charging behavior. The five identified patterns display distinct PEV charging behaviors with respect to parking with charging activity and parking without charging activity. These five clusters indicate that though the PEV drivers have variability 
in their charging profiles, the median for charging durations are similar (1.5 hours to 2.5 hours). However, they have significant durations of parking without charging, which can be conceptualized as "inefficient operation of charging stations." This inefficiency is about $54 \%$ of the total usage time of the charging stations. The GHG emissions analysis suggests this inefficiency, if reduced, can have a positive environmental impact (in terms of GHG emissions savings) resulting from an assumed displacement of gasoline vehicles.

Several extensions to this work are envisioned. First, the analysis precluded consideration of behavioral changes. To address this, a queueing simulation model of station operations could be implemented based on this data, providing insights into shifts in station turnaround under different policies. The queueing simulation can further be used to analyze a policy of maximum allowed time to use public charging stations to reduce this inefficiency. Second, empirical data on charging prior to reaching the stations could be collected providing a clearer picture of charging needs at the station and subsequently could be used to reduce the duration of parking without charging.

\section{Conflicts of Interest}

The authors declare that they have no conflicts of interest.

\section{References}

[1] International Energy Agency, "Global EV outlook 2017 two million and counting," 2017, https://www.iea.org/publications/ freepublications/publication/GlobalEVOutlook2017.pdf .

[2] R. Philip and A. Wiederer, Policy Options for Electric Vehicle Charging Infrastructure in C40 Cities, 2010.

[3] J. Woetzel, S. Sha, and H. Zhang, "Electric Vehicles in Megacities-Shanghai Charges up," 2010.

[4] International Energy Agency, E-Mobility Technology Roadmap, Singapore, 2014.

[5] T. Franke and J. F. Krems, "Understanding charging behaviour of electric vehicle users," Transportation Research Part F: Traffic Psychology and Behaviour, vol. 21, pp. 75-89, 2013.

[6] L. Bunce, M. Harris, and M. Burgess, "Charge up then charge out? drivers' perceptions and experiences of electric vehicles in the UK,' Transportation Research Part A: Policy and Practice, vol. 59, pp. 278-287, 2014.

[7] N. S. Pearre, W. Kempton, R. L. Guensler, and V. V. Elango, "Electric vehicles: how much range is required for a day's driving?" Transportation Research Part C: Emerging Technologies, vol. 19, no. 6, pp. 1171-1184, 2011.

[8] J. Bailey, A. Miele, and J. Axsen, "Is awareness of public charging associated with consumer interest in plug-in electric vehicles?" Transportation Research Part D: Transport and Environment, vol. 36, pp. 1-9, 2015.

[9] F. He, D. Wu, Y. Yin, and Y. Guan, "Optimal deployment of public charging stations for plug-in hybrid electric vehicles," Transportation Research Part B: Methodological, vol. 47, no. 2013, pp. 87-101, 2013.

[10] F. He, Y. Yin, and J. Zhou, "Deploying public charging stations for electric vehicles on urban road networks," Transportation Research Part C: Emerging Technologies, vol. 60, pp. 227-240, 2015.
[11] J. C. Kelly, J. S. MacDonald, and G. A. Keoleian, "Timedependent plug-in hybrid electric vehicle charging based on national driving patterns and demographics," Applied Energy, vol. 94, pp. 395-405, 2012.

[12] L. Gan and S. Low, "Optimal decentralized protocol for electric vehicle charging," Power, vol. 6, no. 1, pp. 1-10, 2007.

[13] B. M. Davis and T. H. Bradley, "The efficacy of electric vehicle time-of-use rates in guiding plug-in hybrid electric vehicle charging behavior," IEEE Transactions on Smart Grid, vol. 3, no. 4, pp. 1679-1686, 2012.

[14] N. Shahraki, H. Cai, M. Turkay, and M. Xu, "Optimal locations of electric public charging stations using real world vehicle travel patterns," Transportation Research Part D: Transport and Environment, vol. 41, pp. 165-176, 2015.

[15] J. E. Kang and W. W. Recker, "An activity-based assessment of the potential impacts of plug-in hybrid electric vehicles on energy and emissions using 1-day travel data," Transportation Research Part D: Transport and Environment, vol. 14, no. 8, pp. 541-556, 2009.

[16] N. Caperello, K. S. Kurani, and J. TyreeHageman, "Do you mind if i plug-in my car? how etiquette shapes PEV drivers' vehicle charging behavior," Transportation Research Part A: Policy and Practice, vol. 54, pp. 155-163, 2013.

[17] M. V. Faria, P. C. Baptista, and T. L. Farias, "Electric vehicle parking in European and American context: economic, energy and environmental analysis," Transportation Research Part A: Policy and Practice, vol. 64, pp. 110-121, 2014.

[18] T. Litman, "Generated traffic and induced travel: implications for transport planning," ITE Journal, vol. 71, no. 4, pp. 38-47, 2001.

[19] United Stated Census Bureau, "U.S. department of commerce," 2017, https://www.census.gov/.

[20] ChargePoint Inc, "ChargePoint Inc," 2017, https://na.chargepoint.com/charge_point.

[21] City of Rochester, "City of Rochester," City of Rochester, 2016, http://www.cityofrochester.gov/evcharging/.

[22] Rochester Downtown Development Corporation, "Rochester Down Town," City of Rochester, 2016, http://www .rochesterdowntown.com/.

[23] Market Ventures Inc., "Rochester public market renovation," 2012, http://www.marketventuresinc.com/index.php/businessplanning.

[24] Monroe County New York, "Monroe County-Ontario Beach Park," Monroe County, 2015, http://www2.monroecounty .gov/parks-ontariobeach.php.

[25] GIS Data, "Monroe County," 2017, https://www2.monroecounty .gov/gis-Data.php.

[26] American FactFinder, "United States Census Bureau," U.S. Department of Commerce, 2017, https://factfinder.census.gov/.

[27] S. Theodoridis and K. Koutroumbas, Pattern Recognition, Academic Press, 4th edition, 2008.

[28] W. W. Recker, M. G. McNally, and G. S. Root, “Travel/activity analysis: pattern recognition, classification and interpretation," Transportation Research Part A: General, vol. 19, no. 4, pp. 279296, 1985.

[29] J. L. Walsh, "A closed set of normal orthogonal functions," American Journal of Mathematics Published by: The Johns Hopkins University Press, vol. 45, no. 1 (Jan., 1923), pp. 5-24, 2016. 
[30] J. B. MacQueen, "Kmeans Some methods for classification and analysis of multivariate observations," Berkeley Symposium on Mathematical Statistics and Probability, vol. 1, no. 333, pp. 281297, 1967.

[31] Idaho National Laboratory, "Advanced vehicle testing activity INL/MIS-11-22490," 2010.

[32] US-EPA, "GHG equivalencies calculator-calculations and references," 2016, https://www.epa.gov/energy/ghg-equivalenciescalculator-calculations-and-references.

[33] http://www.nyiso.com/public/index.jsp, NYISO (Markets \& Operations - Market Data - Graphs), 2016, http://www.nyiso .com/public/markets_operations/market_data/graphs/index.jsp.

[34] U.S.-EPA, "EPA and NHTSA propose to extend the national program to reduce greenhouse gases and improve fuel economy for cars and trucks," 2011. 


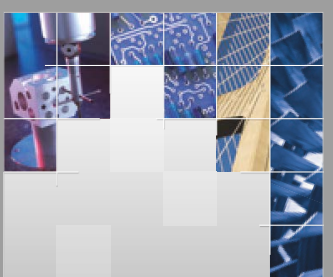

\section{Enfincering}
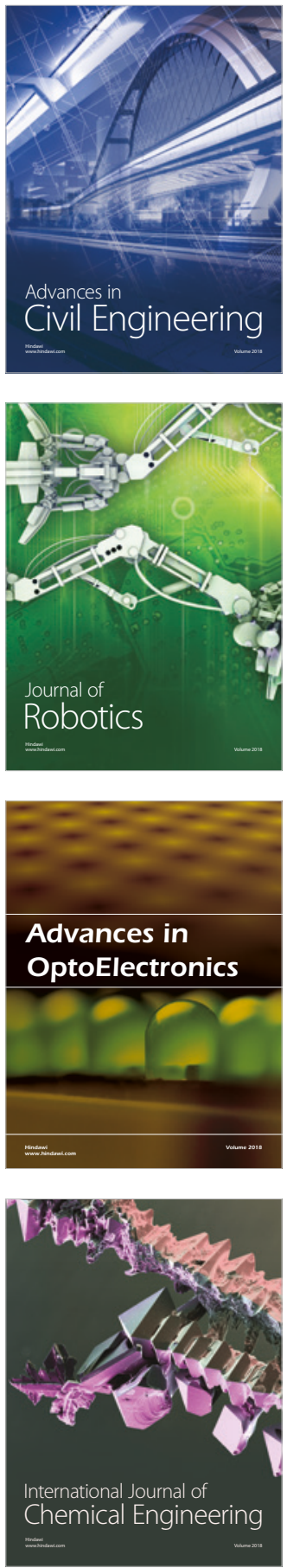

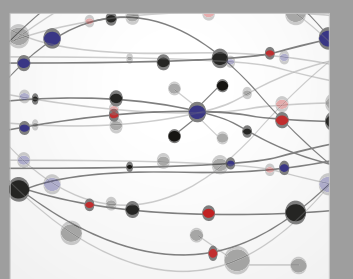

\section{Rotating \\ Machinery}

The Scientific World Journal

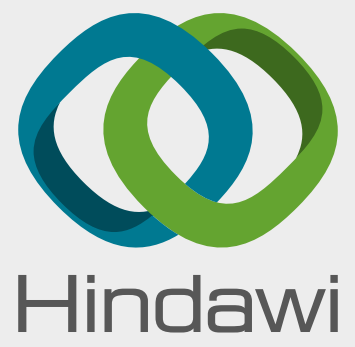

Submit your manuscripts at

www.hindawi.com
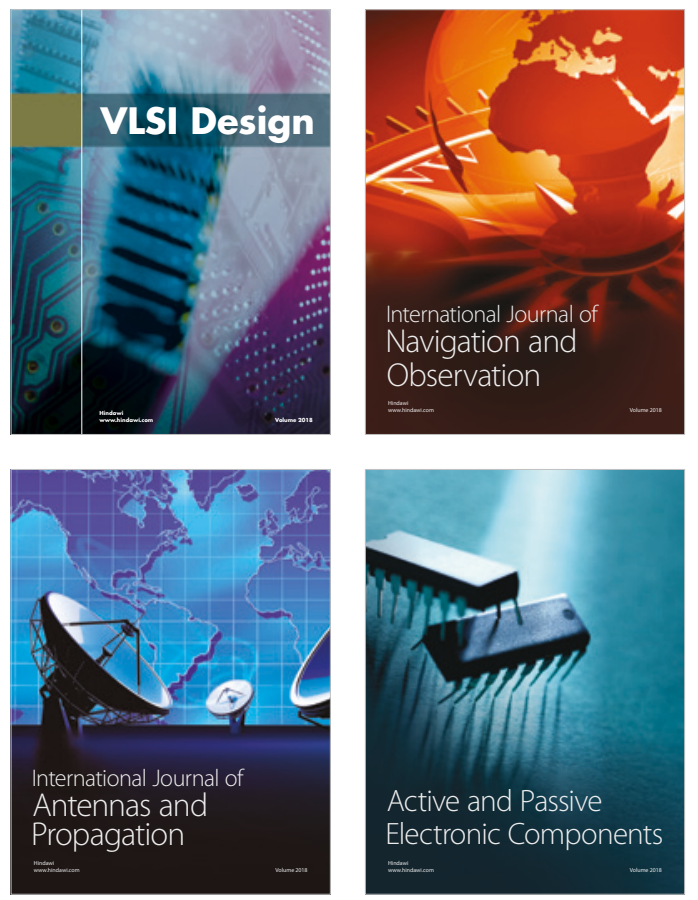
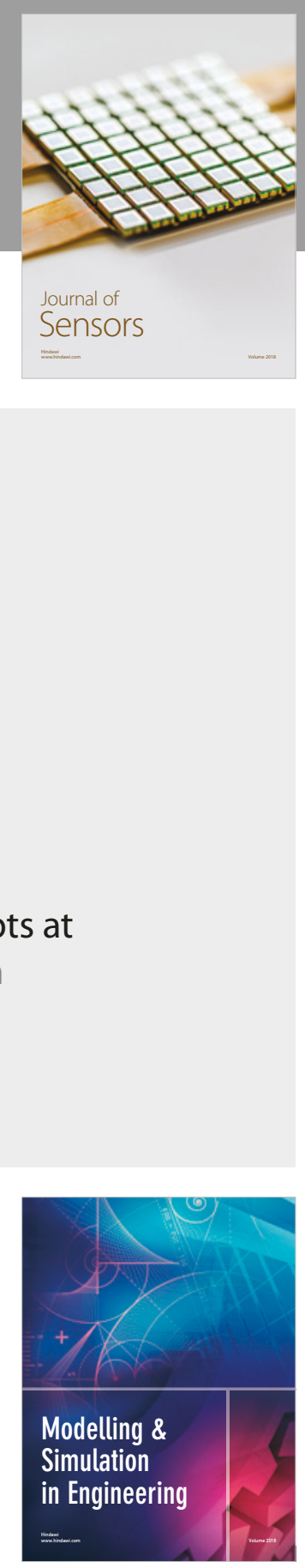

\section{Advances \\ Multimedia}
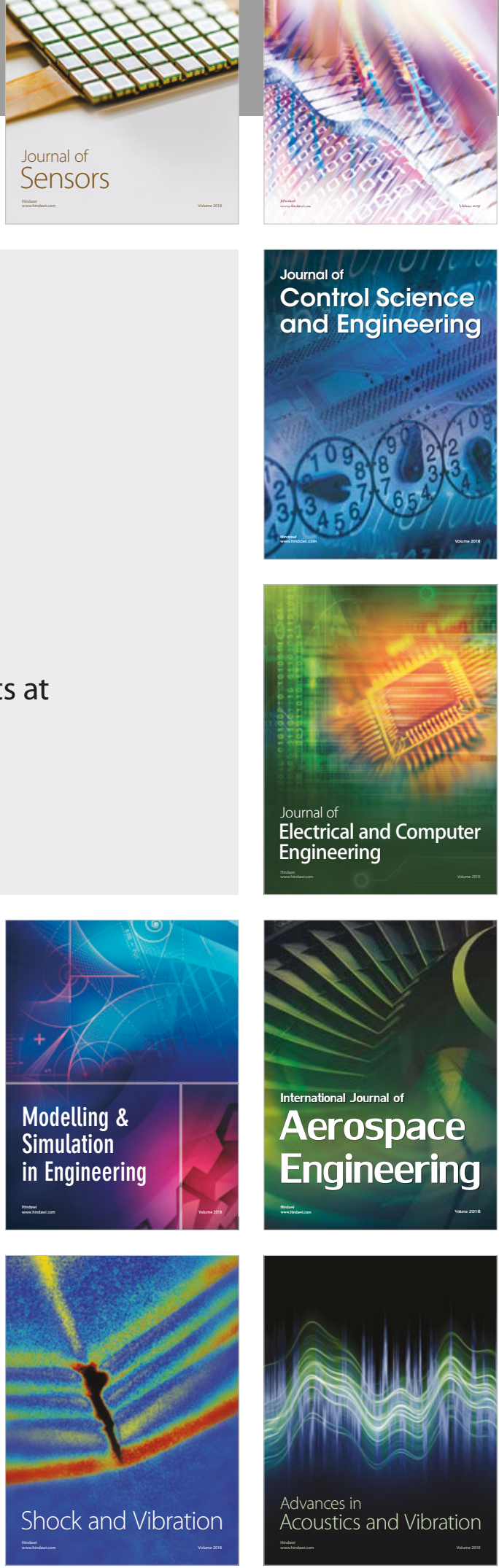